\title{
UN GESTO IMPLACABLE GUARDADO EN NUESTRAS ENTRAÑAS \\ NOTAS REFLEXIVAS SOBRE UNA ENCUESTA \\ ILUMINADORA $^{1}$
}

\section{Rolf Foerster y Sonia Montecino}

En este artículo se reflexiona sobre los modos en que la encuesta CEP (2006) hace emerger una identidad mapuche. Se sostiene que esa identidad se construye en el diálogo con lo no indígena y en las múltiples aristas que develan que ésta no puede comprenderse desde el esencialismo sino más bien desde procesos de larga duración, en los cuales diversos pactos históricos con el “otro” (colonial, republicano) hacen posible una concepción particular mapuche sobre la tierra y sobre la noción de “deuda”. Desde esta escena dialógica, por otro lado, la lectura de los datos de la encuesta permite aproximarse

Rolf Foerster. Doctor en Antropología (Universidad de Leiden). Profesor asociado del Departamento de Antropología, Facultad de Ciencias Sociales, Universidad de Chile.

Sonia Montecino. Doctora en Antropología (Universidad de Leiden). Profesora asociada del Departamento de Antropología, profesora titular de la Cátedra Género de la UNESCO, Facultad de Ciencias Sociales, Universidad de Chile.

${ }^{1}$ Algunas de las reflexiones de este artículo forman parte del proyecto Fondecyt $\mathrm{N}^{\circ} 1050616$ (Poder y liderazgo mapuche en la Provincia de Arauco), dirigido por de Rolf Foerster.

N. del E.: Sobre los resultados de la encuesta mapuche realizada por el CEP (2006), véanse también en esta edición los trabajos de Fernando Zúñiga, Eduardo Valenzuela, Ignacio Irarrázaval y M. de los Ángeles Morandé, Aldo Mascareño, Juan M. Ossio, así como el comentario de Jorge Larraín al artículo de Aldo Mascareño y la presentación de Carolina Segovia y Lucas Sierra.

Estudios Públicos, 105 (verano 2007). 
al "double bind" presente en mapuches y no mapuches y explica cómo al interior de un nuevo contexto de valoración multicultural las políticas públicas y privadas se confabulan para crear un imaginario ambivalente en donde cultura y trasgresión juegan un papel crucial en una sociedad, como la chilena, que ha experimentado (fetichizado) durante siglos el "problema” mapuche sin encontrarle solución. Por último, se sacan a luz ciertas dimensiones de género que evidencian las posiciones sociales y simbólicas de las mujeres mapuches y cómo ellas matizan y complejizan las dinámicas identitarias y sus influjos en el entramado dialógico interno y externo de su cultura.

Esas son las escrituras sacras nuestras del indígena, $y$ les digo nuestras, porque es necesario que el mestizo - aquí hay pocos - entienda que es la única manera de hablar; que él no puede hablar del indio destacándolo hacia fuera como quien tira el lazo. El indio no está fuera nuestro: lo comimos y lo llevamos dentro (Gabriela Mistral, en Pensando a Chile.)

\section{Introducción}

$\mathrm{E}$ n primer lugar deseamos destacar que el valor de la encuesta que comentamos reside en que sus resultados hacen posible replantear una serie de lugares comunes sobre la identidad y la cultura mapuches vinculados a la lengua, a sus costumbres y tradiciones, a sus demandas y anhelos, así como al universo simbólico y político en torno a la tierra. Junto a ello, trae a escena una mirada inédita: por primera vez contamos con una aproximación amplia y sistemática de las percepciones de sus vecinos no mapuches. La sorprendente concordancia de opiniones obliga a un ejercicio de re-conceptualización de nuestra percepción respecto a la "cuestión mapuche”, en la medida que pone de manifiesto que ella está construida de un modo dialógico. Se había pensado hasta ahora que la discriminación sufrida por este pueblo originario transformaba a su cultura en una suerte de refugio, mas hoy parece ser que la "esencia” de lo indígena se constituye en ese diálogo: sus vecinos valoran tanto o más la lengua, los ritos, la cultura mapuches que los propios portadores de esos signos ${ }^{2}$; asimismo ambos

${ }^{2}$ La reciente encuesta UC-ADIMARK (octubre 2006) lo expresa a nivel nacional, así como el vuelco en la manera de encarar la "cuestión mapuche”. Se hizo la siguiente pregunta: "Respecto de los mapuches ¿cuál de estas afirmaciones se acerca a lo que usted piensa? Es mejor que mantengan su cultura, sus costumbres y tradiciones. / Es 
"grupos" aseveran que el "país debe reparar a los mapuches" por la existencia de una deuda histórica; compensación que tiene que realizarse a través de la entrega de tierras; $y$, por último, reviste gran interés la coincidencia sobre el uso de la fuerza como fórmula para recuperarlas, opinión aceptada por sobre el $50 \%$ en los dos agregados.

\section{Principales problema país}

Sin grandes diferencias, mapuches y no mapuches piensan que los “problemas país” son el empleo (43\% y 41\%), la pobreza (43\% y 42\%), la educación (36\% y 32\%), la salud (35\% y 37\%) y la delincuencia (35\% y $39 \%)$; lo que coincide con la visión generalizada del resto de la población que percibe, asimismo, que estas materias son de gran relevancia, aunque según las últimas encuestas (2005 y 2006) la prioridad es la delincuencia. Es interesante señalar que las mujeres mapuches sí ponen mayor énfasis en este último punto (un 37\% de ellas opina que es una cuestión importante).

Desde la experiencia rural, que el empleo constituya el principal "problema país” patentiza, una vez más, la dependencia que las economías domésticas mapuches tienen del mercado de trabajo local, regional o nacional. Si en la década del 80 el 13,7\% del total de sus ingresos provenía de salarios —un 20\% del PEM (programa de empleo mínimo), 15\% de trabajos temporales, $14,5 \%$ de trabajos ocasionales y $1,5 \%$ de trabajos permanentes ${ }^{3}$ - en la década de los 90 esta dependencia salarial ha aumentado considerablemente. En las zonas que nosotros hemos trabajado (Provincia de Arauco) en los últimos años ese aumento ha significado más o menos un $50 \%{ }^{4}$

mejor que se adapten y mezclen con el resto de los chilenos”. La primera afirmación corresponde al actual paradigma multicultural que comienza a generalizarse en Chile en la década de los 80; la segunda, a uno de integración y asimilación que fue dominante, en América Latina, a lo largo del siglo XX. Los resultados de esta encuesta evidencian que el primer modelo es el que hoy prevalece (un 64\% para el ABC1; un 76\% para el C2; un $68 \%$ para el C3; un 65\% para el D; un 60 para el E) y sobre todo en la derecha (un $73 \%$ ella, un $68 \%$ la izquierda y un $65 \%$ el centro).

${ }^{3}$ Bengoa y Valenzuela (1984), pp. 142-143.

4 "Las familias con menos recursos (primer decil más pobre) del país tienen un ingreso mensual autónomo per cápita del hogar de \$63.866; pueden obtener hasta 100.729 pesos mensuales en subsidios estatales, dependiendo de las ayudas a las que postules” (declaración de Clarisa Hardy, ministra de Planificación Nacional, en El Mercurio, 11/10/2006, p. A1.) Sin duda los mapuches han sido y son parte de esas familias que postulan a esos subsidios, incluso "la población indígena accede igual o en mayor proporción que la población no indígena a esta red de prestaciones. En el caso de la población indígena rural, cerca del $10 \%$ de sus ingresos totales son generados por este tipo de subsidios monetarios, proporción muy superior a la no indígena rural, que es de 3,8\%” (MIDEPLAN, 2006, p. 30) 
Con respecto a la confianza en instituciones, las diferencias entre mapuches y no mapuches son mínimas. Destacan la baja confianza en los partidos políticos (9\% y 8\%) y en los tribunales (19\% y $18 \%)^{5}$, no así en la radio (56\% y 59\%), en los carabineros (48\% y 53\%) y en las fuerzas armadas (46\% y $50 \%)$.

A más de alguien sorprenderá que en el acápite "La confianza en las instituciones mapuches”, la CONADI (Corporación Nacional de Desarrollo Indígena) ostente un lugar prioritario $(40 \%)^{6}$, por sobre "el lonko de mi comunidad" (32\%) y la "machi de la comunidad" (31\%). En este contexto también se preguntó por un número significativo de organizaciones mapuches (Admapu, Consejo de Todas las Tierras, Coordinadora Arauco Malleco, etc.) las que al relacionarlas con la pregunta "qué tan representado se siente usted por ellas”, deberíamos reconocer que éstas han ganado un importante lugar en el imaginario político de los mapuches, en especial el Consejo de Todas las Tierras: a un $22 \%$ los representa mucho y a un $32 \%$ los representa un poco.

Sin embargo es preciso destacar las diferencias de género que se producen respecto a estas confianzas. En términos muy generales, las mujeres demuestran dar menos crédito que los hombres a todo tipo de instituciones. En este sentido quizás su propia experiencia, sobre todo en relación con la escasa y a veces nula participación en las organizaciones étnicas y estatales (como la CONADI) las lleva a ser más suspicaces respecto a su adhesión y sentimientos de representación. Por otro lado, y como sugerimos más adelante, las mujeres mapuches portan una percepción de la discriminación más acentuada que los hombres, en la medida en que su posición general en la sociedad chilena es más vulnerable ${ }^{7}$. Quizás por eso su confianza respecto a las fuerzas armadas, los carabineros, la prensa y la televisión, los sindicatos, los partidos políticos, el congreso, etc., sea siempre

\footnotetext{
${ }^{5}$ En los “problemas país” el sistema judicial 8\% y 9\%.

${ }^{6}$ Es interesante notar que se trata de una institución estatal aceptada e internalizada como mapuche-huinca, tanto por los propios indígenas, como por el resto de la población, recuérdese que su Consejo Nacional está conformado, entre otros, por cuatro representantes mapuches, y que, además, se inscribe en la larga tradición de las "instituciones mediadoras" entre el Estado (colonial y republicano) y el pueblo mapuche. Con respecto a estas instituciones J. I.Vergara (2005), p. 36, ha insistido que "el accionar de las instituciones mediadoras tiene un efecto contradictorio: en la medida en que la acción mediadora supone un grado de reconocimiento de la organización socio-política indígena y su cultura, produce una etnificación de las relaciones sociales; mientras que, al mismo tiempo, utiliza esos mismos espacios para manipular y controlar dicha sociedad, esto es, a la vez destruye las formas de poder y la cultura indígena”.

${ }^{7}$ Tal vez ello se explique porque la estigmatización ha sido un proceso más profundamente arraigado en su construcción como género.
} 
menor que la de los hombres. Eso sí, otorgan un mayor grado de crédito que éstos a las iglesias católica y evangélicas (aunque en estas últimas sólo muestren una leve diferencia con los varones) a las radios y a los municipios. Podríamos hipotetizar que estos mayores niveles de preferencia se relacionan con espacios en los cuales ellas son acogidas y protagonistas, y de los que obtienen beneficios palpables, ya sea en el plano de la ritualidad (las iglesias), ya sea en el de subsidios y planes específicos para las mujeres (los municipios) y en el de la información e interacción (las radios). En el caso de las iglesias, sobre todo en las evangélicas, las mujeres pueden acceder a una serie de posiciones que no las discriminan a la hora de participar en igualdad de condiciones en los ritos y en las diversas lecturas sincréticas de las creencias.

Quizás este recelo femenino esté relacionado también con las vivencias de discriminación que la encuesta ilumina. Son precisamente las mujeres quienes se sienten mayormente discriminadas por instituciones como la escuela, en las oficinas públicas (aun cuando comparten con las no mapuches este sentimiento), al buscar trabajo y en los sueldos. Es claro que estas formas de discriminación son generales a las mujeres chilenas, sin embargo, adquieren un claro contenido étnico en el caso de la educación y en la búsqueda de trabajo. Las dimensiones de género unidas a las étnicas y de clase quizás configuren un modo de estar en el mundo donde la desconfianza pueda ganar un lugar preponderante a la hora de evaluar las diversas institucionalidades de las cuales son marginadas y segregadas.

Queda claramente de manifiesto, asimismo, que las mujeres se sienten menos representadas que los hombres en las organizaciones políticas generales y en las propias de su etnia, y no es menor que un 33\% de ellas estima no ser representada por ninguna. Si vinculamos esto a los altos niveles de desconfianza que plantean, podemos pensar que ellas mantienen una brecha considerable de marginalidad y distancia con las instituciones formales, situación que por cierto se liga a las vivencias acentuadas de discriminación que expresan padecer. En este sentido, podríamos decir que las mujeres mapuches, en esta encuesta, estarían mostrando que su posición de género es doblemente desmedrada: tanto al interior de su propio grupo como en el no mapuche ${ }^{8}$.

Estos datos, por cierto, pueden resultar un tanto contradictorios cuando observamos que en el plano de la "aparición" pública, son a menudo las mujeres las que emblematizan la lucha en muchos de los conflictos,

${ }^{8}$ Esto se aprecia con nitidez en las publicaciones de Mideplan respecto a la situación de las mujeres indígenas en general en Chile, las cuales ostentan niveles mayores de pobreza, discriminación y vulnerabilidad social que los hombres indígenas. 
como lo fue el caso de las hermanas Quintremil en Altos Bío Bío o aquella mujer que agredió a un ex director de la CONADI y, recientemente, a un juez en los tribunales de Temuco. Sabemos que ese protagonismo es más bien excepcional, pero lo entendemos justamente como un síntoma en el escenario público de un "femenino mapuche" que no entra en negociaciones políticas y en pactos institucionales, pues al estar y sentirse fuera de ellos, al desconfiar, al ser marginales, sus actuaciones en esa arena son mucho más "subversivas" que las de los hombres acostumbrados al "negocio político". Por otra parte, es posible que la interiorización de la discriminación femenina en cuanto a las instituciones forme parte de esa constelación menos "normativa” respecto a su accionar en lo público.

\section{Problemas y conflicto mapuches}

En relación a esta materia la encuesta propone un giro a los resultados obtenidos en los "Diálogos Comunales"9 (que dieron las bases institucionales al Programa Orígenes y a nuevas orientaciones de la CONADI con respecto al Programa de Tierras) ${ }^{10}$, pues coloca en el nudo de los problemas mapuches la "recuperación de tierras indígenas ancestrales" (35\%), aunque junto a ello también la pobreza (34\%), la educación (30\%) y el empleo (27\%). Desde una mirada de género, si bien las mujeres comparten en gran medida estos problemas, ponen un poco más de énfasis en la educación, y mencionan más que los hombres el fomento y protección de la cultura.

Lo anterior está estrechamente ligado a una interrogante de gran relevancia: “¿Debe el país reparar a los mapuches?” La respuesta afirmativa es muy alta: $91 \%$, como también lo es, aunque menor, la de sus vecinos: un 79\%. La conciencia de reparación por haber sido dañados y la necesidad de compensación por parte de un Estado (¡de quién si no de “él”!) que debe resarcir el agravio, arranca históricamente en el siglo XIX y en las primeras décadas del siglo XX con la implantación del sistema reduccional. Todas las organizaciones e intelectuales mapuches, desde los inicios del siglo XX, marcaron en ese hito la raíz de sus problemas, punto que comparten con la mayoría de sus coterráneos (Foerster-Montecino, 1988).

De modo convergente con las respuestas anteriores, a la cuestión: “¿Cómo debe reparar?”, el 60\% responde: con tierras; un 25\% con educa-

\footnotetext{
${ }^{9}$ Estos fueron realizados en el año 1999 y, según una publicación del Programa Orígenes, "participaron cerca de 4 mil dirigentes y se canalizan más de 2 mil 995 demandas” (2006), p. 6.

${ }^{10}$ Véase el informe del Departamento de Ingeniería Industrial de la Universidad de Chile, “Evaluación en Profundidad del Fondo de Tierras, CONADI”, 2001.
} 
ción y un 12\% con empleo. Y, cosa paradójica, sus vecinos también declaran lo mismo, incluso sus respuestas son levemente superiores a las de los mapuches (63\%). La educación y el empleo caen a un $25 \%$ y $12 \%$ respectivamente. Desde una óptica de género, es bastante evidente que las mujeres mapuches comparten con los hombres el tema de la tierra como núcleo clave de la reparación, sin embargo ellas hacen más referencia que éstos a la no discriminación, a la salud y a "escucharlos", elementos que proponen un "desagravio" que toca a la valoración social y a la consideración, por parte del "otro", de los mapuches como sujetos, como iguales.

Empero, el cuadro de los "problemas y conflicto" es más complejo, ya que la demanda política, que podría bosquejarse frente al tema de la reparación, tiene una expresión mínima: sólo el 2\% piensa en la "representación política" y un $1 \%$ en el "reconocimiento constitucional". En otras palabras la "demanda por tierra" es procesada políticamente — pues es el Estado el llamado a solucionarla — pero su concreción —más tierra— no puede ser leída bajo una fórmula etnonacionalista (tierras autónomas).

Demos una vuelta de tuerca a lo anterior. Si la tierra posee esa centralidad simbólica (daño y reparación) y política (el papel del Estado) para los mapuches (y también para sus vecinos), no resulta extraño, entonces, que el $20 \%$ justifique siempre el "uso de la fuerza" y el $40 \%$ en algunas circunstancias (pero, debemos ser finos en esto pues no significa que literalmente lo lleven a cabo), y es notable que las mujeres lo justifiquen, en este sentido, un poco más que los hombres (42\% y 39\% respectivamente). Sorprende nuevamente que sus vecinos también aprueben el "uso de la fuerza”. Sin duda esto se corresponde con el clima de violencia soterrada que existe en la Araucanía (cuya expresión son los múltiples pequeños incendios intencionales que afectan a las forestales, los juicios por terrorismo a los lonkos, etc.).

¿Cómo interpretar este conjunto de señales que mantienen a la tierra en el núcleo del conflicto (real e imaginario)? ¿Cómo entender esta valoración del uso de la "fuerza propia" con la misma valuación que se da a la "fuerza ajena" (la alta confianza en carabineros y fuerzas armadas)? Sin embargo, también es cierto que no todos los mapuches y vecinos están de acuerdo con el uso de la violencia. ¿Será, entonces, el escudo de armas de la nación el que nos sirva para comprender este fenómeno o para simbolizar esa vacilación que signa nuestra historia en la zona central y en la Frontera: "por la razón o la fuerza", entre el tierno e inocente huemul del sur y el sanguinolento cóndor de la zona central?

Propongamos una última vuelta de tuerca. Si la tierra es tan fundamental, ¿cómo explicar, por un lado, el anhelo de los mapuches que sus hijos 
e hijas sean profesionales, y el deseo que éstos(as) se vayan a vivir a la ciudad? Pensamos que hay aquí un desfase generacional ligado a una estrategia familiar: se sabe (por experiencia ya de varias décadas) que sólo unos(as) pocos(as) podrán seguir viviendo y subsistiendo de la tierra, los otros(as) hijos(as) deberán migrar a las ciudades: y si lo deben hacer ¿por qué no desear que la educación les permita llegar a ser profesionales? ${ }^{11}$

\section{Identidad}

El conjunto de preguntas que nos acercan a la identidad mapuche tornan visible la necesidad de superar las imágenes tradicionales y esencialistas que tenemos sobre ella ${ }^{12}$. Resalta al respecto que las "dos características más importantes que definen a un mapuche" sean, en primer lugar, la lengua - lo que significa situar al mapudungun como el corazón de su identidad - (nuevamente sus vecinos concuerdan con esta opinión) y, en segundo lugar, los apellidos que tienen. Podríamos decir que los patronímicos emergen como una suerte de encarnación de la lengua pues ostentar un apellido mapuche es como hablar o ser hablado por el mapudungun, pero a la vez es ser hablado por los muertos, por los ancestros que portaron la lengua de la tierra.

Es interesante poner atención a dos cuestiones que aparecen con poca relevancia: el "vivir en comunidad" y en "tierras mapuches" (14\% y $13 \%$ respectivamente), como participar en ceremonias o ritos mapuches (3\%) e ir donde la machi (2\%). Estas cuestiones nos proponen una interrogación: ¿ellas implican que las fronteras étnicas son sólo formales (lingüísticas)? Respondemos que sí y no. En el primer caso es afirmativo si el lenguaje se considera como cimiento para el ethos de un pueblo (como piensa Castells, en sintonía con las tesis de Sapir-Wolf). Es negativo si pensamos que el lenguaje no es lo fundante. Igual cosa sucede con los ritos; no podemos olvidar, además, que en numerosas zonas rurales el sincretismo religioso es muy fuerte, y que el nguillatun y la machi forman parte de un ecumenismo local junto a las iglesias cristianas — protestantes

${ }^{11}$ No podemos olvidar tampoco que desde comienzos del siglo XX aparece la reivindicación por educación en las distintas organizaciones mapuches, por ello no es raro que esa bandera de lucha se haya internalizado y transmitido por generaciones, y no es extraño que sean las mujeres (por todas las razones que hemos evidenciado sobre sus sentimientos de discriminación) las que demandan hoy más que los hombres ese derecho.

${ }^{12}$ Sobre la identidad de los mapuches urbanos, véase Aravena (1999) y McFall (1998). 
(anglicanas, metodistas, presbiterianas, etc.), evangélicas (el universo pentecostal, donde los "aliancistas" parecen ser mayoría) y católicas- y no cristianas como los Bahai.

Hay otros dos aspectos que no podemos dejar de mencionar en cuanto a la alta consideración que los(as) mapuches dan al conocimiento y uso del mapudungun como parte clave de su cultura. Por un lado, existe lo que podríamos denominar un "políticamente correcto mapuche" que se vincula con el hecho que el propio discurso político de las organizaciones ha designado y reiterado a la lengua como un elemento frontal dentro de sus demandas, lo cual ha dado pie a políticas estatales y académicas relacionadas con la "educación intercultural bilingüe". Por otra parte, y sobre todo en el universo urbano, muchos de los procesos de "re-etnificación" que se producen allí han puesto como medida de la "mapuchidad" en la ciudad el hablar mapudungun ${ }^{13}$. De ese modo, no es difícil constatar que la lengua emerja con la relevancia numérica con que lo hace. El segundo aspecto, es que desde la tradición oral y la transmisión de la memoria histórica y cultural, los(as) mapuches contemporáneos monolingües en castellano, en su gran mayoría, se las han arreglado muy bien para transmitir a sus hijos(as) un sentido de la tierra que no guarda, conceptualmente, relación con el "occidental" (como lo demuestra la encuesta), las historias de sus linajes, el universo mítico, creencias, etc. De este modo, no podemos engañarnos al pensar que el no hablar mapudungun trae consigo la pérdida de una memoria cultural, sino más bien como diría Walter Ong, desde el castellano (y junto a él el influjo de la escritura) los mapuches recrean en su oralidad rasgos claves para la reproducción de su cultura. La oralidad castellana mapuche - y nos atrevemos a decir, sobre todo la de las mujeres - es un nudo fundamental de la transmisión transgeneracional de una determinada concepción de la historia cultural.

Ahora bien esta imagen "cultural" de la identidad debe ser puesta en relación con los resultados de la pregunta: "Ud. diría que tiene mucha, alguna o nada de sangre indígena”. El 62\% de los mapuches considera que

${ }^{13}$ En algunas organizaciones de mujeres mapuches urbanas se habló de una suerte de "discriminación al revés” que sufrían los(as) mapuches que habían nacido en la ciudad por parte de los mapuches rurales, quienes los(as) interpelaban por su mayor o menor conocimiento de la lengua. Una mujer nos comentó una vez lo siguiente: “ahora algunos dirigentes le ponen a uno un 'mapuchistómetro' que consiste en hablar mapudungun, en hacer los ritos igual que en el campo... Por eso algunos han comenzado a ir a cursos de mapudungun". Este "mapuchistómetro" amenazaba de algún modo la consecución de ciertos beneficios del Estado y producía una tensión entre rural/urbano por la legitimidad (hegemónica) de lo mapuche y por tanto por el poder de las organizaciones frente al mundo huinca y al Estado. 
tiene "mucha" y un 36\% "algo", contrastando fuertemente con sus vecinos no mapuches: un 2\% "mucha” y "algo" un 33\%. Este resultado es concomitante con la valoración de los apellidos que se poseen (basta uno para ingresar a la categoría de indígena). Nos enfrentamos así a una "racialización" de la identidad, un proceso que se viene gestando desde comienzos del siglo XX y que ha transformado "al cuerpo mapuche" en lugar de soberanía ${ }^{14}$. Este proceso, hay que señalar, no es sólo parte de una construcción simbólica mapuche, sino también del espejeo que produce en la sociedad chilena en general, que asiente y refuerza esta noción de "cuerpo otro" definitorio de la "mapuchidad", de un soma que esculpe la diferencia con "lo chileno". Hay que señalar, y ligado a una dimensión de género, que el cuerpo de la mapuche ha sido simbolizado como el sitio de residencia de esa alteridad esperada (por ello, sus propias vivencias de discriminación son tan evidentes).

El análisis de género nos aporta también otros matices a las consideraciones anteriores. Las mujeres al igual que los hombres piensan que la lengua y el apellido definen "lo mapuche", sin embargo agregan que la vestimenta es una característica relevante (21\%), e insisten en que una de las maneras de no perder la cultura se liga al fin a la discriminación (ellas en un $35 \%$ y los hombres en un 28\%) y dan un poco más de relevancia al hecho de casarse entre mapuches y conocer la historia de su pueblo. El señalar que la vestimenta es un rasgo que define la pertenencia étnica pone de manifiesto nuevamente que el cuerpo y los atuendos que lo envuelven son una marca significativa, una señal que indica participar de esa otra cultura, la mapuche. Para nadie es un misterio que la ropa constituye un lenguaje identitario — es decir que habla de semejanzas y diferencias- en todas las sociedades, y en este caso que permite transmitir al "otro" su alteridad. Este énfasis femenino en la vestimenta como signo identitario puede estar afincado en que las mujeres son las que han mantenido con mayor pertinacia que los hombres el uso de sus trajes tradicionales (los cuales no sólo entrañan la ropa en sí, sino una serie de accesorios como la platería que son comprendidos como parte del "vestir" de las mujeres mapuches y que portan una carga simbólica relevante).

Pero, retornemos a la valoración de la lengua, ya que hay una serie de preguntas que permiten evidenciar el juego que se da en torno a ella. Ante la interrogante de si el mapudungun define o distingue a un mapuche, un $82 \%$ de los indígenas rurales dice que sí, aumentando a un $92 \%$ en los urbanos (un $85 \%$ de los vecinos también responde que sí). Si la lengua es tan fundamental nos preguntamos cómo se explican los resultados a la pre-

${ }^{14}$ Véase Pavez (2005), pp. 7-44. 
gunta: “¿Con qué facilidad habla Ud. la lengua mapuche?”: 56\% no la habla ni la entiende (los vecinos: un 92\%), sólo un 4\% la habla mejor que el castellano, un $11 \%$ igual que éste, un $9 \%$ peor que el castellano y un $20 \%$ la entiende, pero no la habla. En concreto: un 76\% no la puede hablar. De modo concomitante son los resultados a la pregunta "¿En qué idioma habla a los niños pequeños?”: el $86 \%$ de los mapuches se dirige a ellos en castellano ${ }^{15}$.

Hay varias maneras de enfrentar esta paradoja de valorar lo que no se practica. Nosotros nos inclinamos por la siguiente hipótesis: la lengua se ha transformado en un significante flotante: designa lo esencial de la identidad y de la cultura mapuche, pero es una esencialidad "abierta" (y, por tanto, se puede llenar de múltiples maneras), equivalente al papel que tienen las banderas o los himnos nacionales para los estados. Sin duda que los hablantes son valorados (más aún si son personas mayores) como también todos aquellos que inician sus "parlas" con el consabido mari mari lamñen, mari mari peñi y asimismo los(as) que poseen uno o dos apellidos indígenas (¡y qué decir del que tiene nombre propio!). Todos(as) ellos(as) son los portadores(as) de la "lengua de la tierra" (mapudungun) y despliegan el significante de lo "muy y bastante importante" para la identidad y la cultura mapuche.

Pero, retomemos un punto crucial: ¿quién es responsable de que la lengua se recupere? Para responder, la encuesta elaboró una interrogante en la cual el 56\% consideró que esa enseñanza debía ser obligatoria en las escuelas para los niños y niñas mapuches. Por tanto la recuperación del mapudungun es entendida, en última instancia, como una responsabilidad del Estado (un Estado del cual ellos son parte integrante). Es obvio entonces que el vínculo entre "esa esencialidad abierta" y Estado se liga directamente al tópico de la deuda, transformándola en "absoluta” (por tanto impagable).

La última pregunta referida a la identidad encara directamente la cuestión de la "nacionalidad”: “¿Se siente (Ud./su pareja) chileno, mapuche, o una mezcla de los dos?" Que un 38\% de los mapuches se sienta mapuche antes que chileno y $37 \%$ mapuche primero y chileno después, podría ser una clara señal de que la "identidad nacional" está en competencia con la "identidad étnica” mapuche, una cuestión que al parecer no se habría producido antes. Recordemos que para una buena parte de la intelectualidad

${ }^{15}$ Los resultados de esta encuesta, en lo que respecta a la cuestión lingüística, son convergentes con los resultados entregados en el trabajo denominado "Estudios del Contexto Sociolingüístico de Comunidades Aymara, Atacameñas y Mapuche de Chile”, cuyo autor es Hans Gundermann (2005). 
mapuche entre 1900 y 1970 lo indígena era consustancial a la raíz de la "raza" chilena, por ello la invocaron contra los colonos y para exigir el reconocimiento de sus tierras (del mismo modo en las marchas y nguillatunes se enarbolaba la bandera chilena ${ }^{16}$ ). Pero, lo notable de este "nacionalismo" mapuche es que se exprese políticamente de una manera tan "tenue" (más tierra) y no de forma "radical": reconocimiento constitucional como pueblo, autonomía territorial, etc.

\section{Cultura}

La pregunta más relevante para indagar en esta dimensión fue: "Señale tres aspectos más importantes para mantener la cultura mapuche". Nuevamente se responde que el hablar la lengua mapuche como máxima prioridad: 55\% para el mapuche rural; 50\% para el urbano y el mismo porcentaje para el no mapuche. Mas también aparece con un $41 \%$ el vivir del trabajo de la tierra (mapuches rurales) y $42 \%$ el conocer la historia del pueblo mapuche (mapuches urbanos).

Un conjunto de aspectos reputados como "esenciales" para la cultura como participar en ceremonias o ritos mapuches, casarse entre mapuches, tienen una baja estima: así sólo un 14\% menciona los ritos mapuches (rurales) y sólo un $16 \%$ valora la endogamia ${ }^{17}$. Siendo claro que los patrones tradicionales del parentesco ligado a fórmulas prescritas de residencia se han transformado, es posible visualizar algunos rasgos que se mantienen como el hecho de que los(as) encuestados(as) opinen que si una mujer no se casa tiene derechos en las tierras de su comunidad. Dos elementos son relevantes desde una perspectiva de género: el hecho de que hoy se acepte que un hombre pueda vivir en la comunidad de su esposa y una alta aprobación a que las mujeres se casen con hombres no mapuches. En el primer caso, se rompe con la regla de la patrilocalidad y en el segundo, con una que en el pasado sólo daba privilegio a los hombres a casarse con mujeres no mapuches. Son muy conocidos los ejemplos en que las mujeres "blancas” pasaron a formar parte de las familias poligámicas, gozando de prestigio aquellos hombres que las tenían como esposas. Ese "objeto del deseo" se ve hoy día desplazado también a las mujeres, y de esa manera los matrimonios mixtos, sobre todo en la ciudad, dan lugar a situaciones de mestizaje

${ }^{16}$ A la pregunta “¿A Ud. le parece bien que en un nguillatun haya una bandera chilena?” El 77,9 de los mapuches rurales responde que sí.

${ }^{17}$ No obstante en algunas áreas rurales estas "ceremonias" son la condensación misma de “lo mapuche”, véase Magnus Edwin George (2005). 
y sincretismo cultural en las cuales, desde nuestras observaciones, el peso de la madre como portadora de "lo mapuche" es muy significativo. Por otra parte, estos casamientos o convivencias con hombres no mapuches en la ciudad se producen con migrantes campesinos, quienes comparten - como nos han expresado algunas mujeres— la identidad de ser "gente del campo".

Hay que señalar, también en relación a la cultura, que aun cuando exista una clara adscripción a la religiosidad católica o evangélica, existe una gran consistencia en el conocimiento sobre los ritos tradicionales, a pesar de que en muchos casos se declara no realizarlos. Esta aseveración no debe eclipsar un fenómeno que ha sido tónica de la sociedad mapuche: su gran capacidad de absorción de elementos huincas al interior de una matriz cultural propia que re-elabora y recrea los sentidos de los mismos. Así por ejemplo, los funerales que en el pasado se realizaban con un gran ceremonial, han debido transformarse por las normas chilenas en relación, por ejemplo, al tiempo del velorio y otras características. Sin embargo, hemos participado de funerales en el campo en los cuales se ha realizado una misa, pero al mismo tiempo se ha mantenido el festín culinario y al difunto se lo ha enterrado con sus herramientas de trabajo agrícola, con comida, con agua, con cántaros de muday (chicha). Lo mismo hemos observado en la ciudad. De este modo, la creencia de que las almas deben atravesar un largo camino para arribar al wenumapu, por lo cual tienen que llevar comida y bebida, no ha desaparecido y pareciera ser que los mapuches piensan que lo que abunda no daña en términos de rituales.

Esto mismo sucede con la pertenencia a las iglesias católica o evangélicas, una serie de significados son trasladados a los cultos (por ejemplo, los sueños y la profecía; y machis que adoptan a la Virgen del Carmen como espíritu protector), por lo cual el declararse católico o evangélico no significa un "blanqueamiento" cultural, sino más bien una condensación de múltiples sentidos donde "lo mapuche" no desaparece, sino que se reinventa. Por ello, es preciso ser cautelosos a la hora de considerar de manera esencialista, sobre todo, los rasgos ceremoniales y religiosos del pasado "que no se practican", la dinámica de la cultura es justamente su permanente cambio y en el caso mapuche, toda su historia pone de manifiesto un inteligente juego de absorciones y relecturas simbólicas que, hasta hoy, hacen persistir el "problema" mapuche dentro de la sociedad chilena.

Este contexto es el que debemos tener en cuenta para leer los resultados de la pregunta "¿Le preocupa la posibilidad de que se esté perdiendo la cultura mapuche?” El 88\% dice que sí (como también los no mapuches: un $72 \%)$. ¿Esta preocupación es por la pérdida de la lengua o por la constatación de la poca significación o realización de lo que ellos consideran como 
prácticas culturales tradicionales? Los datos de la encuesta apuntan a la lengua y al vivir en la comunidad. Estas dos "moradas" (habría que añadir una tercera: la sangre), al parecer, podrán ser ponderadas de manera diferente según los escenarios. La encuesta, tal vez, indica algo que no es difícil percibir en la realidad: si las circunstancias permiten la "lucha por la tierra" se opta por este camino, si esta alternativa se cierra y se abre el sendero "culturalista" como una forma de apoyo a la comunidad, a la lengua, a sus economías (subsidios), los mapuches estarán dispuestos a seguirlo; pero, también si la ruta es la profesionalización de los hijos, mejor todavía.

\section{Tierra y comunidad}

Como lo sostuvimos al inicio, la "tierra mapuche" posee una centralidad compleja, entre otras cosas, por no poder desprenderse ni de los vínculos políticos con el Estado (sistema reduccional-títulos de merced, exención de impuestos, registro de tierras en la CONADI, autorización para venta, etc.) ni tampoco de la "comunidad". Veamos qué nos dice la encuesta sobre este último nexo.

En primer lugar frente a la opción "¿Le gustaría (Ud., sus hijos, sus hijas) irse al campo?” Más del 50\% opta por el sí; y frente a “¿Le gustaría irse (Ud., sus hijos, sus hijas) a la ciudad?”: un $69 \%$ dice que no (hijos un $39 \%$ que no, e hijas un 38\%).

Esta valoración del campo se aprecia también en los resultados de la pregunta “¿Quién está mejor: los mapuches que viven en el campo o los mapuches que viven en la ciudad?” Un $77 \%$ de los indígenas rurales postulan que los que viven en el campo (sólo un 4\% opina los que viven en la ciudad) y un 56\% los mapuches urbanos. También en la pregunta "¿Qué tan importante es que los mapuches no se vayan a vivir a la ciudad?”. Un 77\% de los indígenas rurales y un $55 \%$ de los urbanos creen que es muy importante que no se vayan.

A pesar de esta exacerbada estimación del campo, la "tragedia" es que sólo unos pocos pueden permanecer en él, los y las jóvenes tarde o temprano deberán abandonarlo. Son precisamente los resultados ante la pregunta "Los jóvenes que viven en comunidades... están interesados en quedarse / se quedan porque no tienen otras oportunidades / tarde o temprano se van a ir de la comunidad", los que exteriorizan el "drama": las dos últimas alternativas concentran las opiniones del 31\% y 40\% respectivamente. Este destino "trágico" es respaldado por sus padres: un 67\% "lo/a apoya en su proyecto” y sólo 23\% "trata de que no se vaya”. 
Pero ¿es la comunidad la que no puede retener a los(as) jóvenes o son las familias las que no pueden hacerlo? ¿Qué relevancia tiene la comunidad en los sujetos? ¿Se trata de una “desventura” familiar o comunitaria? Una aproximación a estas cuestiones nos obliga a visualizar los vínculos entre familia (nuclear), comunidad y tierra. Hay un cierto acuerdo entre los estudiosos de la sociedad mapuche que los grupos domésticos (familia) gozan de una gran autonomía frente a la comunidad, incluso algunos investigadores insisten en que esa autonomía apunta directamente al individuo y que es estimulada por una socialización que valora una "ideología de independencia personal” (Melville, 1976) y que fomenta las redes egocentradas (Stuchlik, 1999) $^{18}$.

Es indudable que este peso de lo "individual” repercute directamente en los asuntos de la tierra. Por eso al inquirir la opinión sobre “¿Qué es mejor: que el dueño de la tierra sea... Las personas y sus familias / La comunidad?”, el 86\% marca la primera alternativa (respuesta que tiene la misma ponderación para urbanos y rurales). Esta autonomía individual-familiar llevó a economistas y sociólogos de los años 60 a considerar a los mapuches una suerte de “pequeños burgueses”, olvidando las características del sujeto mapuche y de la particular importancia de la comunidad en los vínculos económicos (Bengoa y Valenzuela, 1984). Prueba de ello es la tensión entre propiedad individual / propiedad privada.

No obstante, hay que comprender que la valoración de la "propiedad individual” está lejos de una valuación plena de la "propiedad privada” y ello queda plenamente demostrado porque:

1) el $59 \%$ de los mapuches rurales opina que "no deberían poder hipotecarse las tierras sin permiso del gobierno” (sólo un 20\% que podría hacerse sin ese permiso);

2) el 68\% de los mapuches rurales y el 54\% de los urbanos estiman que las tierras no deberían poder venderse a no mapuches (sólo el 22\% de los rurales piensa lo contrario);

3) el $64 \%$ de los mapuches rurales y el $40 \%$ de los urbanos no "estaría dispuesto a vender" sus tierras (a pesar que el precio ofrecido sea bueno).

Corolario de ello es, entonces, que un segmento significativo de mapuches construyen una narración, una ficcionalización sobre la tierra, que no se acopla a la “modernidad” (la tierra como mercancía), sino a una

${ }^{18}$ Para una discusión desde la perspectiva de capital social, véase a Durston, Duhart, Miranda, et al. (2005). 
"tradición” en la que se unen o sintetizan varias: la étnica, la estatista, la comunitaria y la ecológica. Las actuales y pasadas tensiones en la Araucanía se explican por este choque.

Por último y de no menor importancia: ¿cuál es la magnitud de la demanda por tierras? Hasta los 70 ésta se limitaba a la recuperación de las usurpadas en los espacios deslindados por los títulos de merced (se la calcula en 100 mil hectáreas). No obstante, desde los 80 esa demanda comienza a sobrepasar el sistema reduccional. Dos razones explican esta situación. En primer lugar, la dirigencia mapuche, bajo el escenario de valoración de lo étnico, considera normal recuperar sus espacios territoriales históricos, y la emergencia de identidades locales, como nagche, wenteche, lafkenche, etc., o supra-locales como el wallmapu así lo expresa. En segundo lugar, hay un argumento histórico más reciente: la Reforma Agraria “desacralizó" la estructura de la tenencia de la tierra en la Araucanía, creando las bases para una "nueva" redistribución del tan preciado bien (Correa, Molina y Yáñez, 2005). El mejor ejemplo se encuentra en la Provincia de Arauco. Allí la Reforma Agraria de Alessandri propició un imaginario que hasta hoy día gravita en la demanda mapuche: colonias indígenas que implicaron 60 hectáreas por familia ${ }^{19}$. Este sueño se concretó después de las tomas de Pangal y Huape (1962) en el corazón de Arauco, creándose las colonias "Rosa Ester Rodríguez de Alessandri” y “Federico Peña”, las que significaron 5.100 hectáreas para los mapuches. Hay que tener presente que bajo el sistema reduccional en Arauco se entregó sólo un total de 9.699 hectáreas (Foerster, 2004).

\section{Pacto}

La concordancia de opiniones entre los mapuches y sus vecinos —respecto al valor de la cultura, de la lengua, de la tradición, de la tierra, etc.- es sorprendente y merece un comentario. En primer lugar, porque se contradice con uno de los resultados de la encuesta: el 77\% de los mapuches piensa que es importante que no se los discrimine y, es obvio, que esa discriminación es ejercida fundamentalmente por sus vecinos (a pesar de que éstos opinan, asimismo, en un 66\%, que ello es muy relevante).

En segundo lugar, es plausible, en base a las investigaciones existentes, formular la hipótesis de que los vecinos aprecian de una manera ambigua a los mapuches. Se trata de un double bind de larga data, que se ha ido re-significando a través del tiempo, últimamente con la postmoderni-

${ }^{19}$ Lo que contrasta con el promedio de más o menos 10 hectáreas que hoy entrega la CONADI. 
dad y el multiculturalismo. En el siglo XVIII adquirió la forma de una queja sobre lo contradictoria que era la política de los parlamentos, que hacía de unos “salvajes” una "nación”; en el siglo XIX, Vicuña Mackenna se condolía de nuestra imposibilidad de actuar en la Araucanía a la manera del far west americano y lo atribuía al relato fundacional de Chile (La Araucana de Ercilla); y, en el siglo XX, se popularizó por la prensa la imagen del “cordón suicida” para hablar de las comunidades y el apoyo que recibían de las políticas proteccionistas del Estado. Ahora bien, lo novedoso que revela la encuesta es que si antes estimábamos del mapuche su pasado (porque también era el nuestro) y despreciábamos su presente (borracho, flojo, etc.), hoy apreciamos ambas dimensiones temporales al resignificar no sólo su cultura (la lengua) sino también su pasado (la deuda) y sus derechos (tierra).

En tercer lugar, si toda identidad es dialógica (Tylor, 1993), hay que aceptar entonces que los vecinos son hoy (y claramente no lo fueron en el pasado) uno de los mayores promotores de la "cultura” mapuche. ¿Pero es un asunto sólo de los vecinos? ¿No es también el Estado (CONADI), las ONG, las universidades y las empresas forestales (con sus políticas de buena vecindad) lugares en los cuales hoy se valoriza y se promueve la cultura mapuche? Pero este aprecio tiene otra arista: el Consejo de Todas las Tierras y la Coordinadora Arauco Malleco han impulsado todo un proceso de etnificación y de etnonaciolización que pasa justamente por revalorar la lengua, sus costumbres y sus autoridades tradicionales. Lo prodigioso de todo esto es que hoy en día una machi puede participar por la mañana en un acto oficial de accionistas de Endesa, al mediodía compartir con la Presidenta de la República promoviendo la educación intercultural, a media tarde en el lanzamiento de un libro sobre la cultura mapuche en el Museo Precolombino promocionado por el Banco Santander, en la tarde en un acto del Consejo de Todas las Tierras exigiendo el reconocimiento constitucional de los mapuches como pueblo, y en la noche curando a los enfermos en el box de algún hospital de Santiago.

Reconozcamos entonces que existe una tensión, un double bind, en la Araucanía y a lo largo de todo Chile en las maneras de vincularse con lo mapuche ${ }^{20}$. Esta encuesta exhibe ese double bind no sólo en las relaciones entre los mapuches y sus vecinos sino también en el propio seno indígena con respecto a la lengua, a la tierra, a la comunidad y a la migración. Posiblemente ese double bind tenga como centro algo que Gabriela Mistral eviden-

${ }^{20}$ Para el período 1973-1989, véase Kellner (1994). 
ció hace muchos años hablando de una de las figuras emblemáticas de nuestro pasado-presente-futuro:

El gesto de Caupolicán implacable sobre el leño que le abre las entrañas, está tatuado dentro de nuestras entrañas (Chile, 1923).

Un último comentario. ¿Se podrían interpretar los resultados de esta encuesta desde la perspectiva del pacto? Nuestra idea es que si leemos la historia de las relaciones entre la sociedad mapuche y la chilena a través de esta noción, ello nos permite una comprensión más rica y compleja de esos nexos. El primer pacto, el colonial, hizo posible la constitución de la frontera, la que fue sancionada por la política barroca de los parlamentos; un nuevo acuerdo se gestó en el siglo XIX entre los lonkos y el gobierno de Pérez que dio origen a la ley de 1866, cuyo espíritu era el reconocimiento de las tierras mapuches ${ }^{21}$ y que se tradujo malamente en el sistema reduccional; un tercer pacto se gestó en 1952 entre la máxima organización mapuche -la Corporación Araucana - y el gobierno de Ibáñez que permitió la creación de una institución estatal (DASIN), dirigida por indígenas, que velara por las tierras y la producción mapuche; un cuarto pacto es el de Imperial (1989) en el cual los temas de reconocimiento y de reparación son basales. Desde nuestra mirada la encuesta pone al descubierto cómo ese pacto (inseparable de los anteriores) no es sólo un asunto entre la elite política indígena y la chilena, sino que se expresa a nivel cotidiano, entre los mapuches y sus vecinos no indígenas.

El psicoanálisis lacaniano nos ha enseñado que "Lo que 'mantiene unida' a una comunidad profundamente no es tanto la identificación con la Ley que regula el circuito cotidiano 'normal' de esa comunidad, sino la identificación con una forma específica de transgresión de la Ley, de suspensión de la Ley (en términos psicoanalíticos, como una forma específica de goce)"22.

Debemos reconocer que este lugar de transgresión gozosa de la ley lo ocupa hoy el mapuche —algo que El Mercurio nos señala cada día en sus primeras páginas al graficar las tomas de tierras por parte de una comunidad o el golpe de una lamñen a un juez-. Éste es un pacto perverso que el pacto político no puede olvidar. Otro pacto perverso es insistir en que el mapuche ocupe un único lugar posible: el de la víctima o el de un sujeto condenado a la folclorización (la esencialización de lo mapuche).

\footnotetext{
${ }^{21}$ Sobre este "pacto", véase Toledo (2001).

22 Zizek (2005), p. 89.
} 
Pensamos que debemos encarar abiertamente estas perversiones en la búsqueda de una política multicultural, que no obvie las duras y agraviantes condiciones materiales de las comunidades y de las personas, su complicada dependencia económica con el Estado y sus instituciones, así como ese gesto arcaico tatuado en nuestras entrañas que Gabriela Mistral nos obliga a recordar para siempre.

\section{BiBLIOGRAFÍA}

Aravena, Andrea: "La Identidad Indígena en los Medios Urbanos: Procesos de Recomposición de la Identidad Étnica Mapuche en la Ciudad de Santiago”. En Boccara y Galindo, Lógica Mestiza en América. Temuco: Instituto de Estudios Indígenas Universidad de La Frontera, 1999.

Bengoa, José (compilador): La Memoria Olvidada. Historia de los Pueblos Indígenas de Chile. Santiago: Cuadernos Bicentenario, 2004.

Bengoa, José y Eduardo Valenzuela: Economía Mapuche. Santiago: PAS, 1984.

Boccara, Guillaume: Guerre et Ethnogenèse Mapuche dans le Chili Colonial. París: L'Harmattan, 1998.

Bunster, Ximena: “Adaptation in Mapuche Life: Natural and Directed”. Tesis doctoral, Columbia University, 1968.

Castells, Manuel: Economía, Sociedad y Cultura. La Era de la Información. Madrid: Alianza Editorial, 1998.

CEP (Centro de Estudios Públicos): "Estudio de Opinión Pública: Los Mapuche Rurales y Urbanos Hoy. Mayo 2006”. Santiago: CEP, 2006.

Correa, Martín, Raúl Molina y Nancy Yáñez: La Reforma Agraria y las Tierras Mapuches. Chile 1962-1975. Santiago: LOM, 2005.

Departamento de Ingeniería Industrial, Universidad de Chile: "Evaluación en Profundidad del Fondo de Tierras y CONADI”. 2001.

Durston, John, Daniel Duhart, Francisca Miranda, et al.: Comunidades Campesinas, Agencias Públicas y Clientelismo Político en Chile. Santiago: LOM, 2005.

Edwin George, Magnus: "Mapuche Person, Mapuche People. Individual and Society in Indigeneous Southern Chile”. En London School of Economics and Political Science, 2005.

Faron, Louis: Los Mapuches, su Estructura Social. México: Instituto Indigenista Interamericano, 1969.

Antüpaiñamko. Moral y Ritual Mapuche. Santiago: Ediciones Mundo, 1977.

Foerster, Rolf: “¿Pactos de Sumisión o Actos de Rebelión? Una Aproximación Histórica y Antropológica a los Mapuches de la Costa de Arauco”. Tesis doctoral, Leiden, Holanda, 2004.

Foerster, Rolf y Jorge Vergara: "Etnia y Nación en la Lucha por el Reconocimiento. Los Mapuches en la Sociedad Chilena”. En Hans Gundermann, Rolf Foerster y Jorge I. Vergara, Mapuches y Aymaras. El Debate en Torno al Reconocimiento y los Derechos Ciudadanos. Santiago: RIL Editores, 2003.

Foerster, Rolf y Sonia Montecino: Organizaciones, Líderes y Contiendas Mapuches: 1900-1970. Santiago: CEM-PEMCI, 1988. 
González, Héctor: "Propiedad Comunitaria o Individual. Las Leyes Indígenas y el Pueblo Mapuche”. En Nütram, 3, 1986.

Gundermann, Hans: "Estudios del Contexto Sociolingüístico de Comunidades Aymaras, Atacameñas y Mapuches en Chile”. En Huechullán Arrue et al., Descripción del Contexto Sociolingüístico en Comunidades Indígenas de Chile. Santiago: Mineduc/Mideplan, Estudios en EIB, 2005.

Kellner, Roger: “The Mapuche during the Pinochet Dictatorship (1973-1990)”. Tesis doctoral, University of Cambridge, 1994.

McFall, Sara: Keeping Identity in its Place. Culture and Politics among the Mapuche of Chile”. Tesis doctoral, St Cross College, Oxford University, 1998.

Mallon, Florencia: La Sangre del Copihue. La Comunidad Mapuche de Nicolás Ailío y el Estado Chileno 1906-2001. Santiago: LOM, 2004.

Marimán, José: “El Nacionalismo Asimilacionista Chileno y su Percepción de la Nación Mapuche y sus Luchas”. En www.soc.uu.se/mapuche, 2000.

Marimán, Pablo: “Tierra y Legislación Indígena: Una Mirada desde el Programa del Movimiento Mapuche (1910-1970)”. En Liwen, 4, 1997.

Marimán, Pedro: “Algunas Consideraciones en Torno al Voto Mapuche”. En Liwen, 2, 1990. “La Diáspora Mapuche: Una Reflexión Política”. En Liwen, 4, 1997.

Melville, Thomas: The Nature of Mapuche Social Power. Tesis doctoral, The American University, 1976.

MIDEPLAN (Ministerio de Planificación Nacional): Memoria Nuevo Trato 2000-2006. Santiago: 2006.

Mistral, Gabriela: “Chile” [1923]. En Jaime Quezada (compilador), Pensando a Chile. Una Tentativa contra lo Imposible. Santiago, Chile: Cuadernos Bicentenario, 2004.

Ong, Walter: Orality and Literacy: The Technologizing of the Word. Londres: Methuen, 1982.

Pavez, Jorge: "Cartas y Parlamentos: Apuntes sobre Historia y Política de los Textos Mapuches”. En Cuadernos de Historia (Dep. de Ciencias Históricas, Universidad de Chile) $\mathrm{N}^{\circ} 25,2005$.

Pinto, Jorge: De la Inclusión a la Exclusión. La Formación del Estado, la Nación y el Pueblo Mapuche. Santiago: Universidad de Santiago, Colección IDEA, 2000.

Programa Orígenes: Mira el Futuro desde tu Origen. Santiago: Mideplan, 2006.

Reuque, Rosa Isolde: Una Flor que Renace: Autobiografía de una Dirigente Mapuche. Ed. y traducción Florencia Mallon. Santiago: DIBAM, 2003.

Stuchlik, Milan: La Vida en Mediería. Santiago: Soles Ediciones, 1999.

Toledo, Víctor: "En Segura y Perpetua Propiedad. Notas sobre el Debate Jurídico sobre Derechos de Propiedad Indígena en Chile”. En Actas $4^{\circ}$ Congreso Chileno de Antropología. Santiago, 2001.

Tylor, Charles: "La Política del Reconocimiento". En Amy Gutmann, Stefen C. Rockefeller, Michael Walter, et al.: El Multiculturalismo y la "Política del Reconocimiento”. México: FCE, 1993.

UC-Adimark: “Encuesta Bicentenario 2006”. En www.uc.cl

Vergara, Jorge Iván: La Herencia Colonial del Leviatán. El Estado y los MapuchesHuilliches (1750-1881). CIDHE, Universidad Arturo Prat, 2005.

Zizek, Slavoj: Las Metástasis del Goce. Buenos Aires: Paidós: 2005. 